Supplement of Hydrol. Earth Syst. Sci., 24, 3815-3833, 2020

https://doi.org/10.5194/hess-24-3815-2020-supplement

(c) Author(s) 2020. This work is distributed under

the Creative Commons Attribution 4.0 License.

(c) (1)

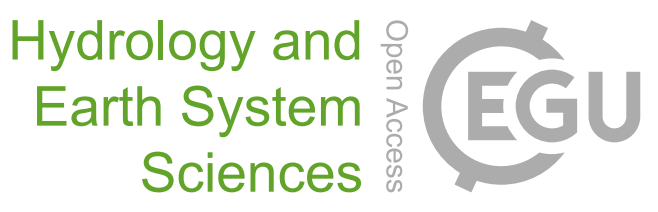

Supplement of

\title{
Risks and opportunities for a Swiss hydroelectricity company in a chang- ing climate
}

\section{Kirsti Hakala et al.}

Correspondence to: Kirsti Hakala (kirsti.hakala@unimelb.edu.au)

The copyright of individual parts of the supplement might differ from the CC BY 4.0 License. 


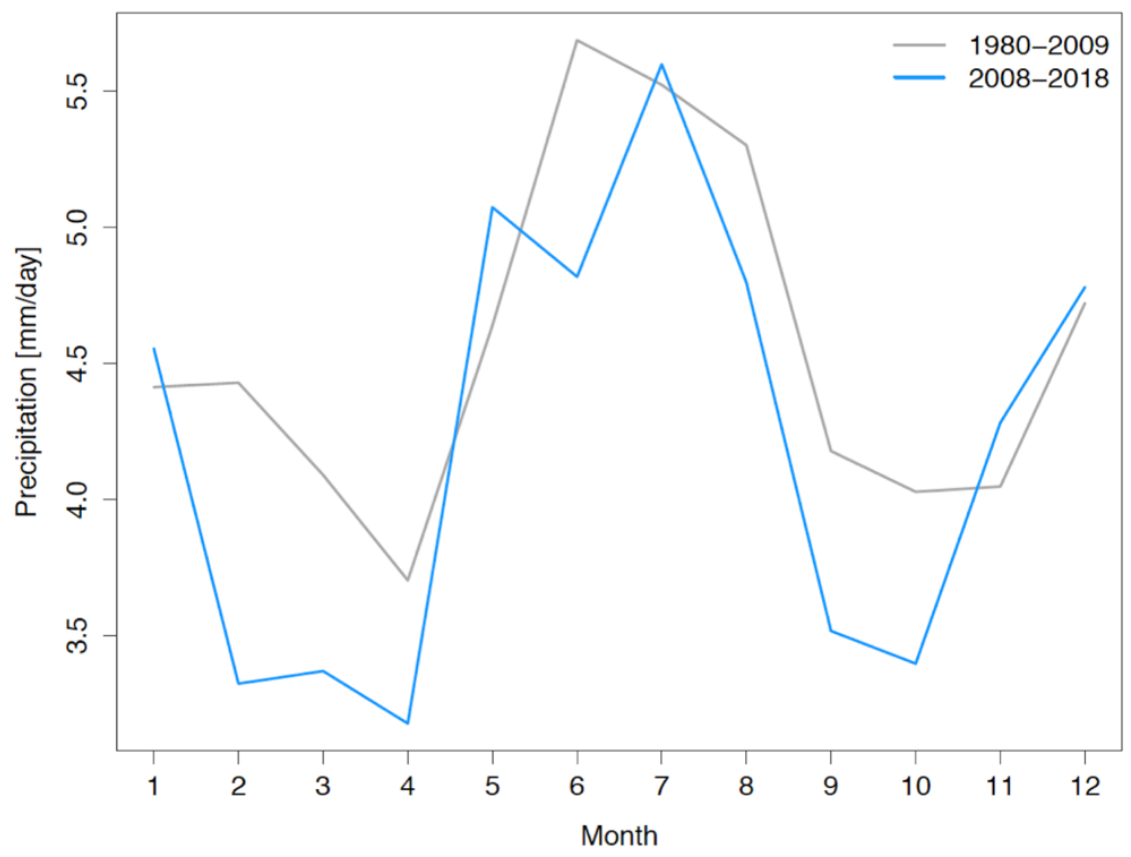

S1: Long-term seasonal variation of precipitation for the Vernex catchment over two different time periods: (i) 19802009, which represents the data used to force $H B V$ and generate $Q_{\text {ref, }}$ and (ii) 2008-2018, which is the period over which HBV was calibrated and validated, based on the Meteoswiss gridded data product (Frei and Schär, 1998; Schwarb, 2000). 


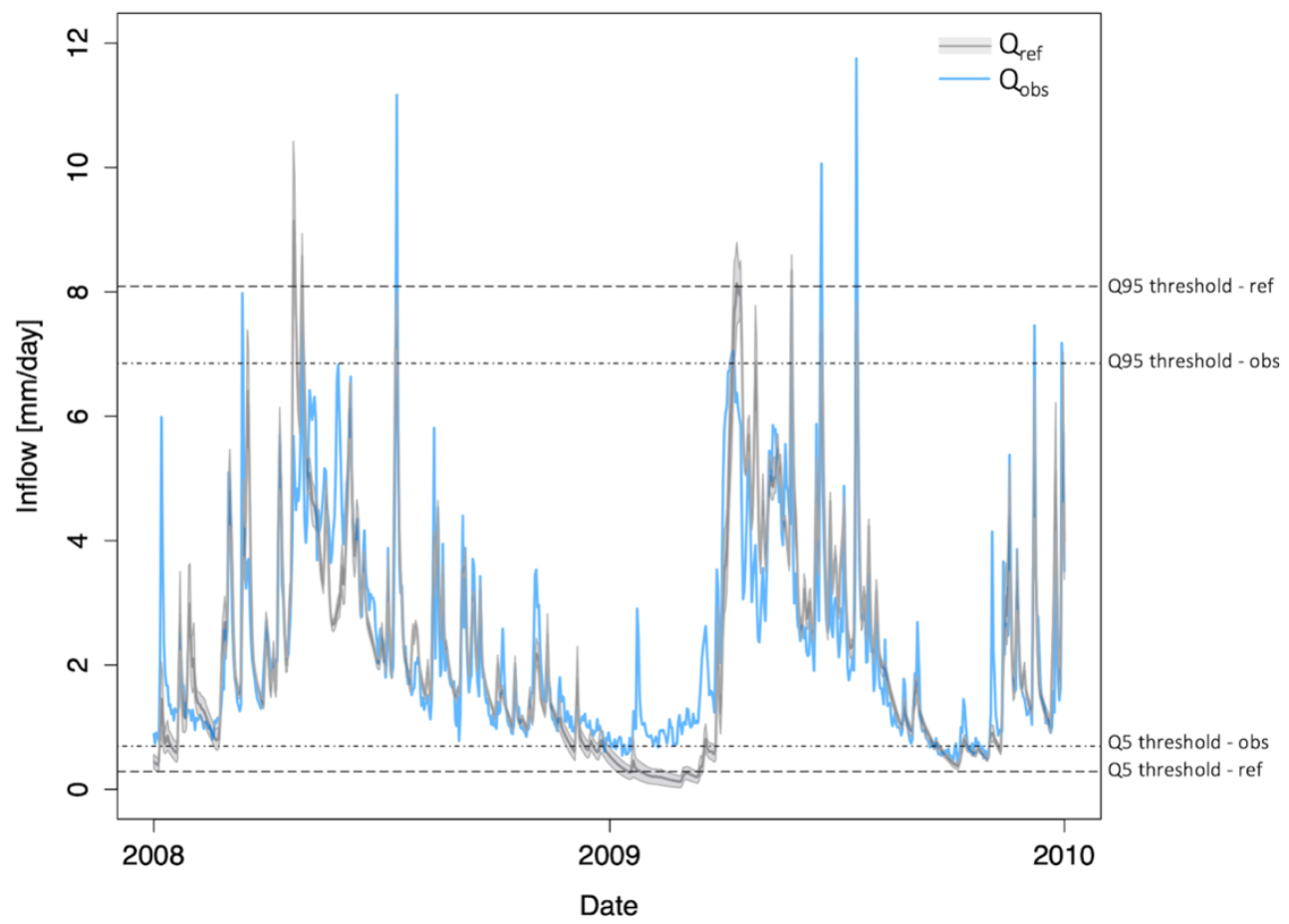

S2: Inflow time series from $Q_{\text {obs }}$ (blue) and $Q_{\text {ref }}$ (gray) are compared for the Vernex catchment over their shared period (2008-2010). The dashed lines represent the Q5 and Q95 thresholds calculated using $Q_{\text {obs }}$ data over 2008-2018 and $Q_{\text {ref }}$ data over 1980-2009. 

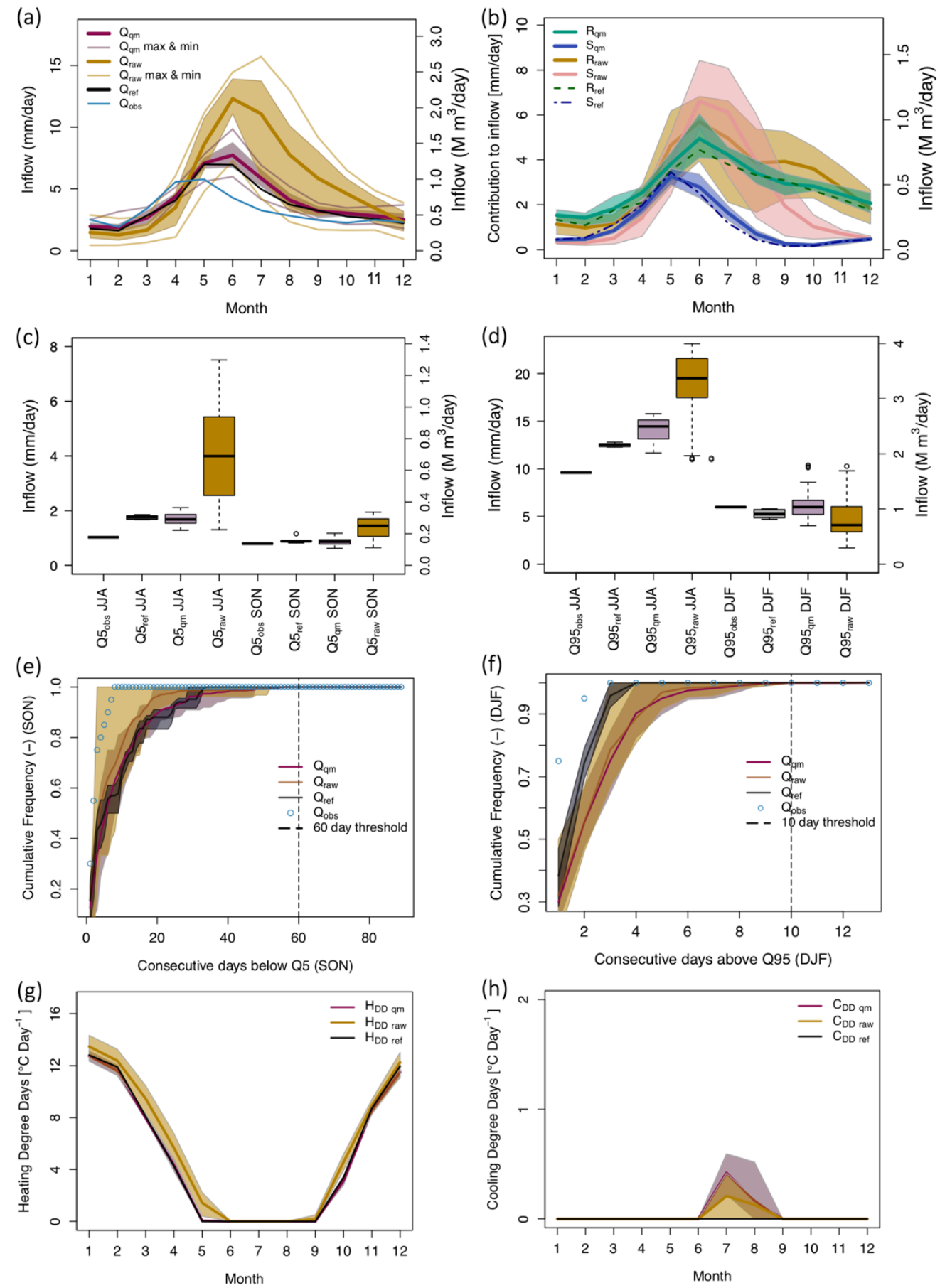

S3: Performances of calibration of $\mathrm{HBV}$ and bias correction treatment are shown for each index for the Montsalvens catchment. When observational data were not available, then only bias correction performance is shown (plots e and f). All simulated data cover the period of 01-01-1980 to 31-12-2009, except for $Q_{\text {obs }}$ data which spans the period of 0110-2008 to 31-08-2018. Plots a, b, g, h depict long-term monthly means. 

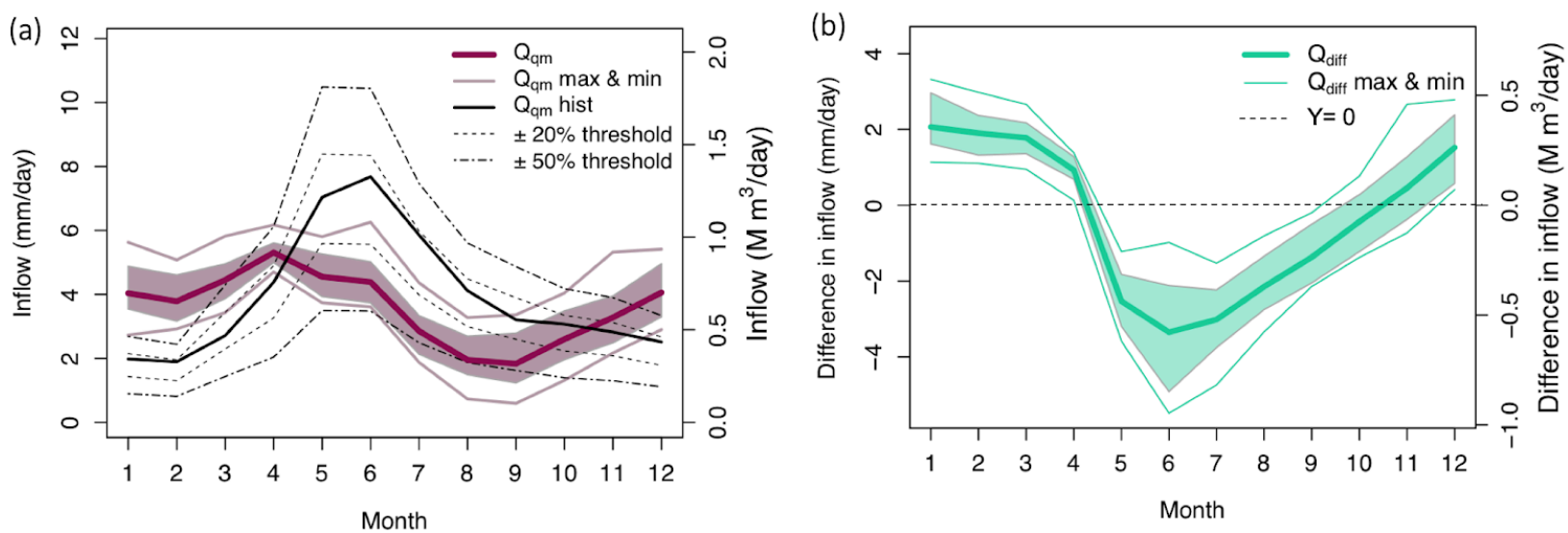

S4: (a) Long-term mean monthly discharge $1980-2009\left(Q_{q m} h i s t\right)$ and for the 2070-2099 $\left(Q_{q m}, R C P\right.$ 8.5) for the Montsalvens catchment. The mean (solid lines) and likely range (shaded areas) are shown, where the likely range represents two thirds of all 660 simulations of all GCM-RCM bias corrected simulations. The two thresholds are based on the mean of the simulations forced by observed climate data $\left(Q_{\text {ref }}\right.$ over the period of 1980-2009). (b) Longterm mean monthly change in inflow (2070-2099 with respect to 1980-2009) is shown for the Montsalvens catchment. 


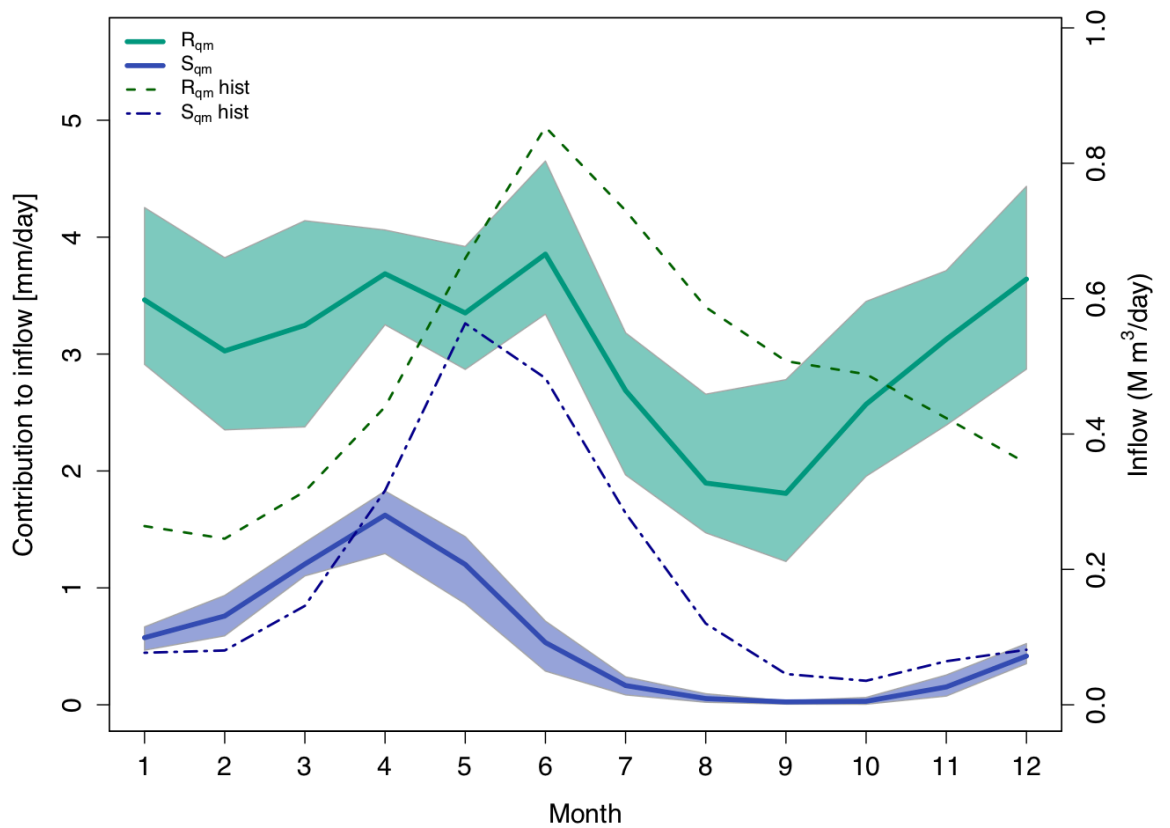

S5: Mean monthly contribution of rain ( $R$, green) versus snow (S, blue) to inflow entering the Montsalvens reservoir. Two periods are compared: $1980-2009\left(R_{q m}\right.$ and $S_{q m}$ hist $)$ and 2070-2099 $\left(R_{q m} \& S_{q m}\right)$. All projections shown are simulations under RCP 8.5. The mean (solid lines) and likely range (shaded areas) are shown, where the likely range represents two thirds of all 660 simulations. The dashed lines indicate the mean of the reference simulations. 

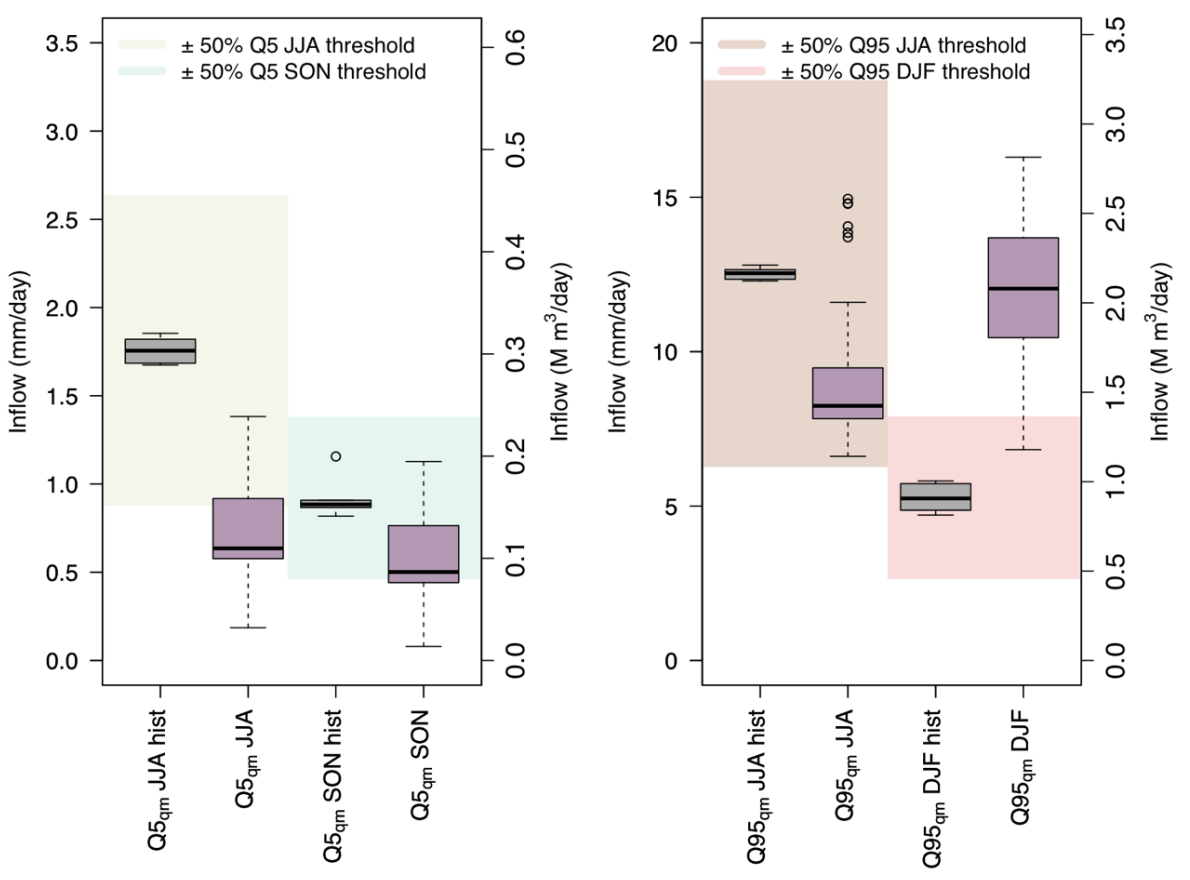

S6: (a) Box plots are shown for low flow (Q5) and (b) high flow (Q95) signatures, where the historical period (gray boxes; 1980-2009) is compared to the future period (purple boxes; 2070-2099) for the Montsalvens catchment. All projections shown are under the influence of the RCP 8.5 climate change scenario. For each signature, an associated $\pm \mathbf{5 0} \%$ threshold is designated by a shaded polygon. Instances where the simulations exceed their associated $50 \%$ threshold represent a level of change that is of interest to Groupe $E$. The values corresponding to these thresholds are based on the mean of simulations when forced by observed climate data $\left(Q_{\text {ref }}\right)$ over the period of 1980-2009. 

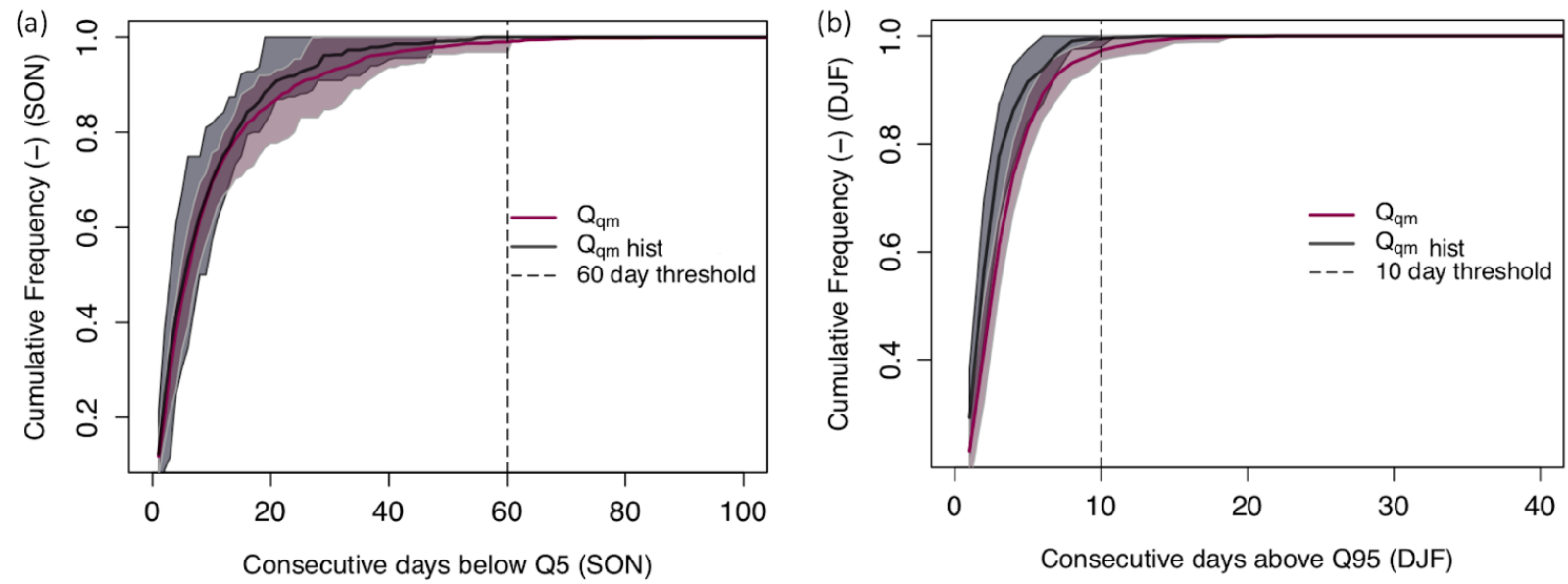

S7: Cumulative distribution functions (CDFs) are shown, where the historical period (1980-2009; gray) is compared to the future period (2070-2099; purple) for the Montsalvens catchment. (a) CDFs for consecutive days below Q5 are shown for the SON season, and a 60-day threshold is indicated by a black dashed line. (b) CDFs of the consecutive days above Q95 are shown for the season of DJF, and a 10-day threshold is shown by a black dashed line. Instances where the simulations exceed their associated threshold represent a level of change that is of interest to Groupe $E$. The mean (solid lines) and likely range (shaded areas) are shown, where the likely range represents two thirds of all 660 simulations of all GCM-RCM bias corrected simulations. 

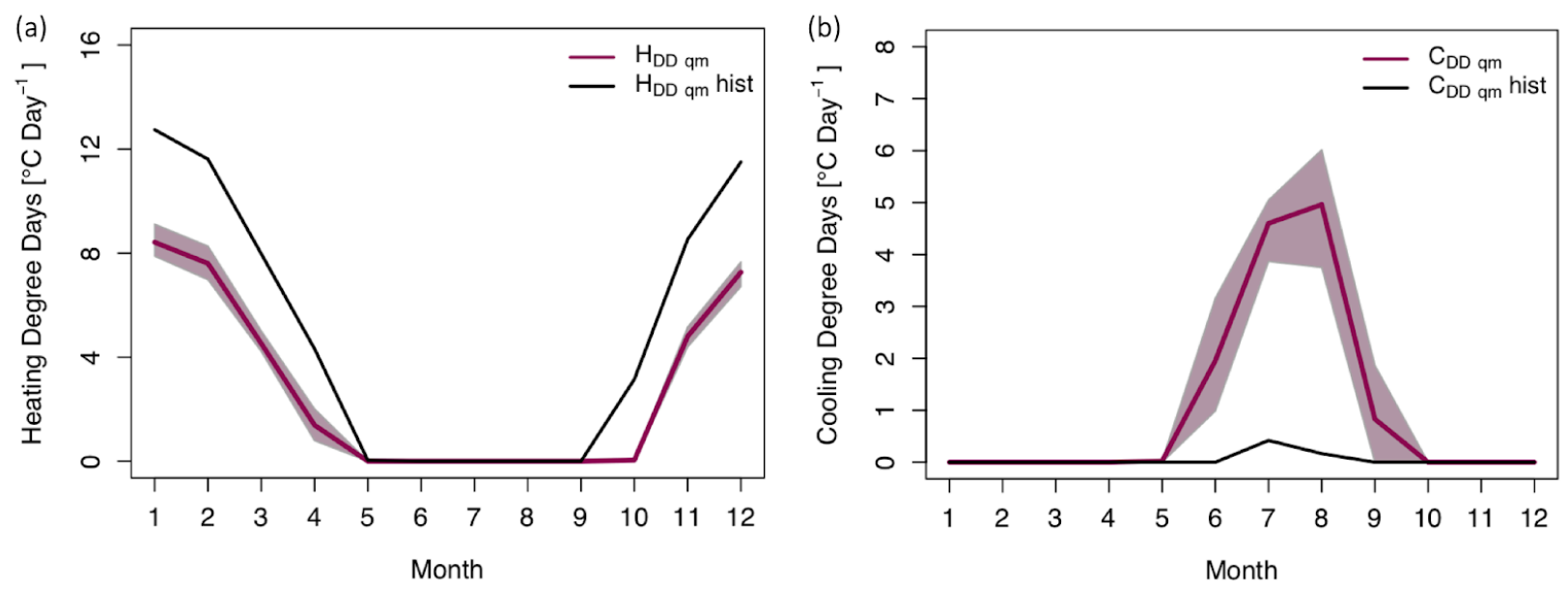

S8: (a) $H_{D D}$ and (b) $C_{D D}$ are shown over a long-term mean monthly cycle for the Canton of Zurich. The mean of the historical simulations (1980-2009; gray) are compared to the future simulations under the influence of RCP 8.5 climate change scenario (2070-2099; purple). The mean (solid lines) and likely range (shaded areas) are shown, where the likely range represents two thirds of all 660 simulations of all GCM-RCM bias corrected simulations. A threshold of $13{ }^{\circ} \mathrm{C}$ was used within the calculation of $\mathrm{H}_{D D}$ and $18.3^{\circ} \mathrm{C}$ was used for the calculation of $C_{D D}$ in order to denote when air temperatures would trigger a consumer to use additional electricity for heating $\left(H_{D D}\right)$ and cooling $\left(C_{D D}\right)$. Groupe $E$ prescribed all thresholds, and the method was adapted from Gaudard et al. (2013). 